\title{
Prevalence, intensity, and impacts of non-cutaneous lesions of lumpy skin disease among some infected cattle flocks in Nile Delta governorates, Egypt
}

\author{
Abdelmoneim A. Ali ${ }^{1}$ - Ahmed N. F. Neamat-Allah ${ }^{2}$ [ $\cdot$ Hamdi Abd El-maguid Sheire $^{1} \cdot$ Rania I. Mohamed $^{3}$
}

Received: 12 February 2021 / Accepted: 8 July 2021 / Published online: 24 July 2021

○ The Author(s), under exclusive licence to Springer-Verlag London Ltd., part of Springer Nature 2021

\begin{abstract}
Lumpy skin disease (LSD) is one of the major viral diseases still causing great economic losses among breeding flocks of Egypt. This study was designed to focus light on non-cutaneous lesions (prevalence, intensity, and impacts) among necropsied LSD infected cattle. We selected some dairy and beef flocks (Frisian breed) located in 3 governorates (Sharkia, Dakahlia, and Kaloubia) in Nile delta, Egypt, in the period from January 2019 to January 2020 for our survey study. The case history of farms declared no previous vaccination of examined farms. The clinical signs, morbidity, and mortality rates were recorded. Average morbidity and mortality percentage were $22.28 \%$ and $6.59 \%$, respectively. PCR for specimens from liver, kidneys, heart, lungs, testis, udder, trachea, and lymph node indicates presence of amplicon capripoxvirus gene product at molecular weight size $192 \mathrm{bp}$. Postmortem lesions of necropsied and emergency slaughtered were recorded. The main detectable histopathology lesions among the infected animals were orchitis (75\%), mastitis in immature and lactating udder (66.66\%), and necrotic hepatitis (77.77\%), disseminated vasculitis (61.11), glomerulonephritis (55.55), myocardial degeneration (50\%), and serous atrophy of coronary fats (38.88\%), lymphadenitis (88.88\%), necrosis and depleted lymphoid tissue of spleen (38.88\%), necrotic myositis $(77.77 \%)$, tracheitis (16.66\%), and pneumonia (interstitial bronchopneumonia) (44.44\%) besides intra-cytoplasmic inclusions bodies in skin (33.33\%). It could be concluded that higher mortalities of LSD may be due to systemic infection of infected animals which had great impact on economic losses among breeding flocks.
\end{abstract}

Keywords Capripoxvirus. LSD $\cdot$ PCR $\cdot$ Non-cutaneous lesions $\cdot$ Prevalence $\cdot$ Gross $\cdot$ Microscopic

\section{Introduction}

Lumpy skin disease (LSD) is a viral pox disease of cattle caused by capripoxvirus, in the family Poxviridae. It is characterized by pyrexia, eruption of nodules on the skin, mucous membranes, emaciation, and enlarged lymph nodes. Various strains of capripoxvirus are responsible for

Abdelmoneim A. Ali

Abdelmoneim.ahmedali@yahoo.com

1 Department of pathology, Faculty of Veterinary Medicine, Zagazig University, Sharkia Province, 1 Alzeraa Street Postal Code 44511, Zagazig City, Egypt

2 Department of Clinical pathology, Faculty of Veterinary Medicine, Zagazig University, Sharkia Province, 1 Alzeraa Street Postal Code 44511, Zagazig City, Egypt

3 Department of pathology, Agriculture Research Center, Provincial Lab, Animal Health Research Institute, Mansoura, Egypt the disease; yet, they are not the same strains which causes sheep and goat pox (Amenu et al. 2018; Limon et al. 2020). Moreover, it causes temporary or permanent loss of milk production, lowered or complete loss of fertility in bulls, and sometimes abortion of pregnant cattle as well as permanent damage to animal hides (Alsalihi 2014).

LSD virus transmitted primarily by insect bites (Jarullah 2015). Firstly, LSD was documented in Egypt in 1988 where it was recognized clinically in Suez Canal governorates then extent to the neighboring governorates in the summer of the same year and apparently over wintered with little or no manifestations as reported by Salib and Osman (2011). In the period of 5 to 6 months, it had been spread to most of Egyptian governorates with $45 \%$ morbidity and the mortality rate reached $10 \%$ (Ali et al. 1990). During summer of 2006, epidemic of LSD were recorded in several Egyptian governorates. The economic impact of LSD results from carcass condemnation as the result of secondary infection. Moreover, LSD constitutes a serious and major problem 
for breeders than for veterinarians, because of the major economic losses, and the expenses of the care and control program and different forms which appear among the cattle flocks. In spite of vaccination program for cattle by usual sheep, pox virus vaccine waves of infection may developed at different intervals which follow by significant economic losses. The majority of previous authors described cutaneous lesions of LSDV with little confident on other organs as superficial lymph nodes, skeletal muscles, udder, and testis (Neamat-Allah 2015; Neamat-Allah and Mahmoud 2019). In the late period, LSD became pandemic and severe among governmental and private flocks located in different provinces of Egypt similar to highly pathogenic avian influenza (H5N1) which infected domestic fowls (Ali et al. 2015). Higher mortalities and morbidity rates among some flocks in Delta Egypt governorates were seen with variable developed and disseminated lesions in some necropsied infected cattle. The later may be attribute to some viral mutation and high virulence of capripoxvirus isolate or wide tropism of virus (Stalker 2007; Zachary and McGavin 2017). So, this study was designed to focus light on non-cutaneous lesions (prevalence, intensity, and impacts) among necropsied LSDinfected Frisian cattle of various ages. We selected some dairy and beef flocks located in 3 governorates (Sharkia, Dakahlia, and Kaloubia) in Nile delta, Egypt, within the period from January 2019 to January 2020 for our survey study.

\section{Materials and methods}

\section{Cattle}

During period from January 2019 to January 2020, 1225 Frisian cattle with different age and sex located in 3 governorates (Sharkia, Dakahlia, and Kaloubia) in Nile delta, Egypt, were surveyed for clinical signs and postmortem lesions in necropsied cattle.

\section{Ethical approval}

Study was achieved in accordance with the standards set by Animal Research Ethics Usage Initiative at Zagazig University, Egypt, and experimental protocols were approved by the official animal ethics agency.

\section{Polymerase chain reaction}

Tissue specimens from liver, lungs, heart, testes, udder, kidneys, and trachea in addition to lymph node were pooled and homogenized and kept in $-20^{\circ} \mathrm{C}$ for identification of LSDV using PCR and LSDV Ismailia 88 strain used as positive control as primers: Oligonucleotide: Oligonucleotide were designed according to Binepal et al. (2001) for amplification of the supplement gene of capripoxvirus. The primers used in the PCR reactions were produced by Metabion International AG Company, GmbH, Germany. The primers were conventional kept in lyophilized form and re-suspended in Tris/EDTA (T/E) buffer (PureLink ${ }^{\mathrm{TM}}$ ) with a final concentration of 100 pmol $\mu \mathrm{L}^{-1}$ and were considered to intensify a specific segment of $192 \mathrm{bp}$. The primer sequences for PCR amplification were as follows: forward primer, $5^{\prime}$-TTTCCT GATTTTTCTTACTAT- $3^{\prime}$ and the reverse primer, 5' AAA TTATATACGTAAATAAC-3' (Zeedan et al. 2019). DNA extraction was done agreeing to Wallace et al. (2007) by 0.5 $\mathrm{mL}$ of infected sample suspension processed with $20 \mu \mathrm{L}$ proteinase $\mathrm{K}$ (with a final concentration, $100 \mu \mathrm{g} \mathrm{mL}^{-1}$ ) at 56 ${ }^{\circ} \mathrm{C}$ for $2 \mathrm{~h}$. One hundred $\mu \mathrm{L}$ phenol: chloroform: iso-amylalcohol (25:24:1) was added and mixed by reverse then centrifuged at $13,000 \mathrm{rpm} / \mathrm{min} / 5 \mathrm{~min}$; then, the upper aqueous layer was transported to a micro centrifuge clean tube, and 2.5 volumes absolute ethanol and $1 / 10$ volume of $5 \mathrm{~mol} \mathrm{~L}^{-1}$ sodium acetate ( $\mathrm{pH}$ 5.3) were added and mixed thoroughly. The DNA was precipitated at $-20{ }^{\circ} \mathrm{C}$ overnight and pelleted by centrifugation at high speed $\left(13,000 \mathrm{rpm} / \mathrm{min}^{-1}\right)$ for 15 min. The pellet was washed once with $70 \%$ ethanol and then centrifuged at $12,000 / \mathrm{rpm} \mathrm{min}^{-1} / 10 \mathrm{~min}$ then air-dried and re-suspended in $50-\mu \mathrm{L}$ T/E buffer (PureLink ${ }^{\mathrm{TM}}$ ). Normal noninfected samples were included as a negative control sample.

\section{Histopathological studies}

Specimens from majority of internal organs including udder, testis, lung, liver, heart, kidneys, lymph node, spleen, trachea, and subcutaneous muscles beside skin lumps were collected from necropsied cattle and then fixed in $10 \%$ neutral buffered formalin solution, dehydratedin $70-100 \%$ gradual ethanol, and embedded in paraffin. Five-micrometer paraffin sections were prepared and then stained with hematoxylin and eosin ( $\mathrm{H}$ and $\mathrm{E})$ and examined microscopically Elseweidy et al $(2017,2019)$ and Neamat-Allah et al. (2020).

\section{Results}

\section{Clinical signs}

The signs varied in severity from mild to severe with cutaneous lesions as papules, which varied from small or large nodules $(0.5-3 \mathrm{~cm})$ in diameters and finally scab formation which maybe sloughed leaving ulcer or healed skin involving the majority of skin surface including head, neck, shoulder, inguinal area, genital organs, and limbs (Fig. 1). Sometimes, the aforementioned lesions accompanied with general signs of fever, inappetence, salivation, nasal discharge, and enlarged superficial lymph node with or without corneal opacity and emaciation followed by death or emergency 


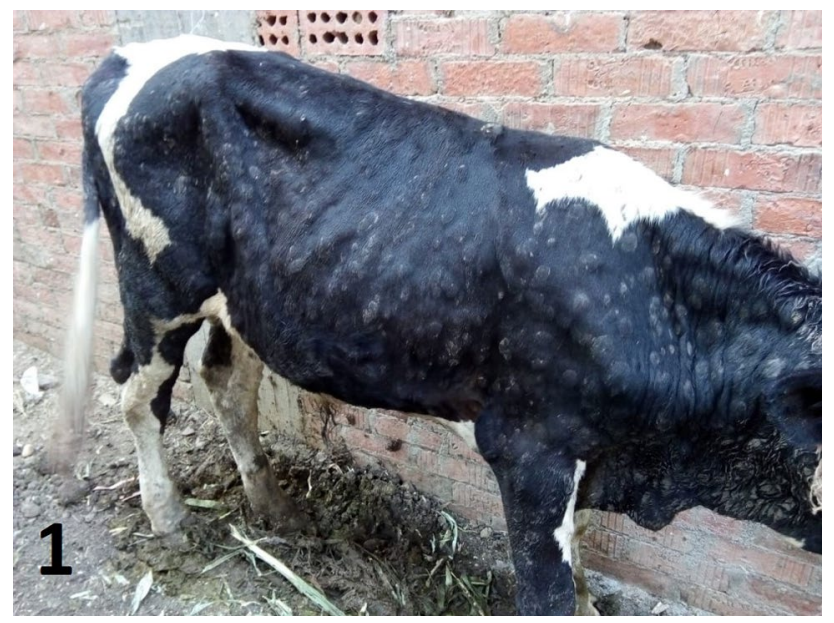

Fig. 1 Cattle showing generalized skin lumps allover the body with a few a scab formation, ulceration and enlarged prefemoral lymph node

slaughter. The morbidity percentage among three surveyed governorates Sharkia, Dakahlia, and Kaloubia was 17.5, 21.73 , and 26.66, respectively, with average total morbidity $22.28 \%$. High mortalities in the three surveyed governorates represented by $7.14,8.0$, and 5.46 respectively with average total mortality $6.59 \%$ due to emergency slaughter (Table 1 ).

\section{PCR}

LSDV DNA were detected in pooled internal organs, tissue specimens, and skin of necropsied cattle which indicates (lanes 1-4) (192 bp) in stained 1\% agarose gel electrophoresis, along LSDV Ismailia 88 strain as reference (lane 5) and 50 bp DNA ladder, and lane 6 was negative control sample (Fig. 2)

\section{Macroscopically}

Gross lesions represented by variable pox lesions in the majority of cases which usually extended deeper to involve subcutaneous and skeletal muscles. Sub cutis appeared soft and pale in color with the presence of gelatinous fluid. Skeletal muscles were firm and paler in color. Enlarged and edematous lymph nodes and sometimes containing dark red areas on their cut surfaces. The skin of udder had cutaneous eruption which extended to involve teats beside indurated and firm glandular tissue in some quarter of dairy cattle. Scrotum of examined bulls had firm skin nodules with atrophied and edematous testes in addition to pale or grayish foci on its surface. Parenchymatous organs of the necropsied animals mainly liver and kidneys were enlarged and contain pale or grayish areas on its cut surfaces. Spleen of some cattle was atrophied and dark red in color. A few examined heart of emergency slaughtered cattle appeared flabby

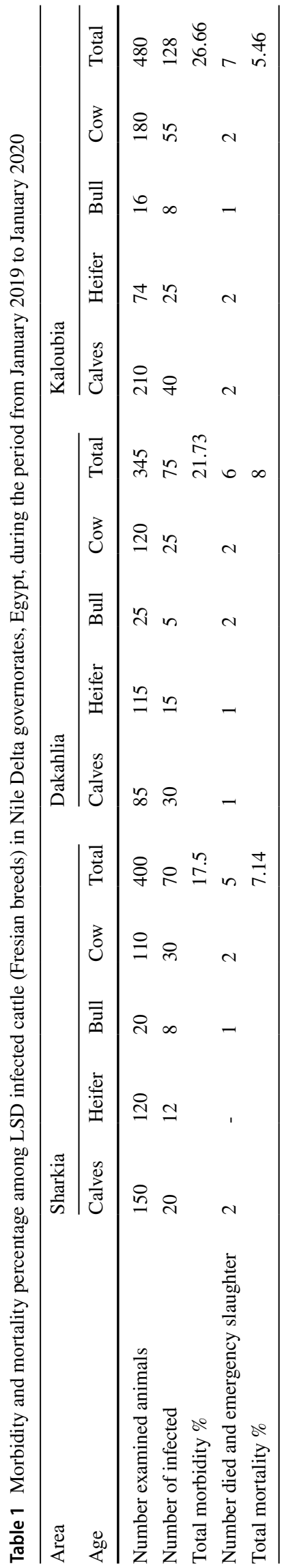




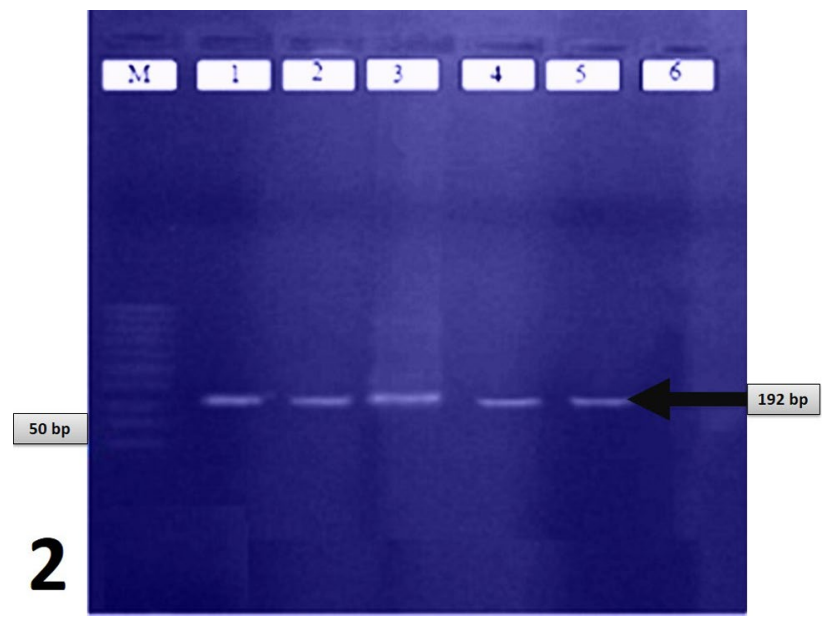

Fig. 2 LSDV DNA prepared internal organs pooled tissue specimen (lanes 1-4) (192 bp) in stained agarose gel electrophoresis, along LSDV Ismailia88 strain as reference (lane 5) and 50 bp DNA ladder, and lane 6 was negative control sample

with slightly soft cardiac muscles beside pale streaks on its surface and gelatinous coronary fat. Tracheal and bronchial exudate with pale consolidated areas incrainio-ventral or diaphragmatic lobes of lungs could be seen in a few necropsied cases.

\section{Microscopically}

Cutaneous lesions represented by epidermal hyperplasia, ballooning degeneration, spongiosis, vesicles, pustules, and crust together with multiple intra-cytoplasmic eosinophilic inclusion bodies were common in epidermis and skin adnexa (Fig. 3). Early, exudative cellulitis either serofibrionous or

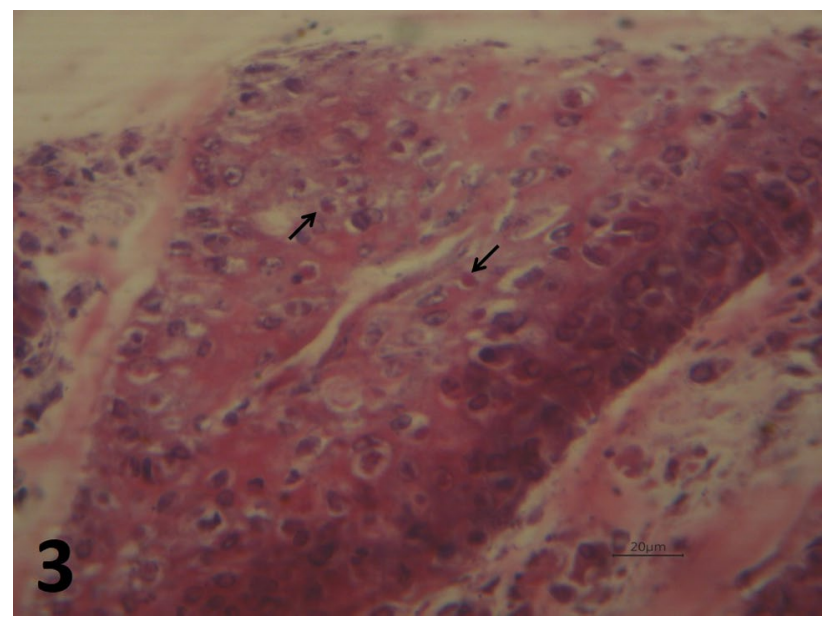

Fig. 3 Skin of Frisian cattle showing ballooning with spongiosis of superficial epidermis and numerous intra-cytoplasmic inclusions bodies (arrow) H\&E

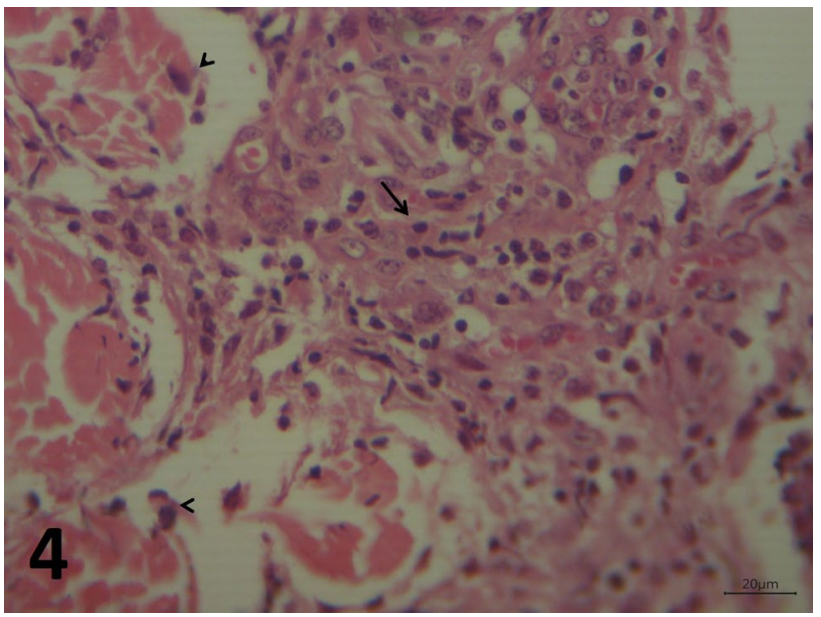

Fig. 4 Skeletal muscle of bull showing necrotic myositis (arrow) with focal calcification (arrow head) H\&E

fibrinopurulent with or without bacterial colonies was seen in dermis and subcutaneous tissue. Later on, fibrosis with mononuclear cells replaced the necrotic muscle fibers. Necrotizing myositis with or without calcification beside thrombosis of blood vessels was common in the majority of skeletal muscles (Fig. 4). The lymphoid tissue (lymph node and spleen) suffered from lymphoid depletion and necrosis with proliferation of reticuloendothelial cells besides expanded setae by exudate suggestive lymphadenitis (Fig. 5). Sometimes, hemosiderin pigment could be seen either as free pigment or engulfed by macrophages within some lymph node. The immature mammary tissue showed interstitial edema and numerous neutrophils infiltration among ill-developed glandular tissue (mastitis). Lactating glands showed inflammatory process characterized by necrotic epithelium of duct and alveoli with or without retained secretion within the alveolar lumina and little inflammatory

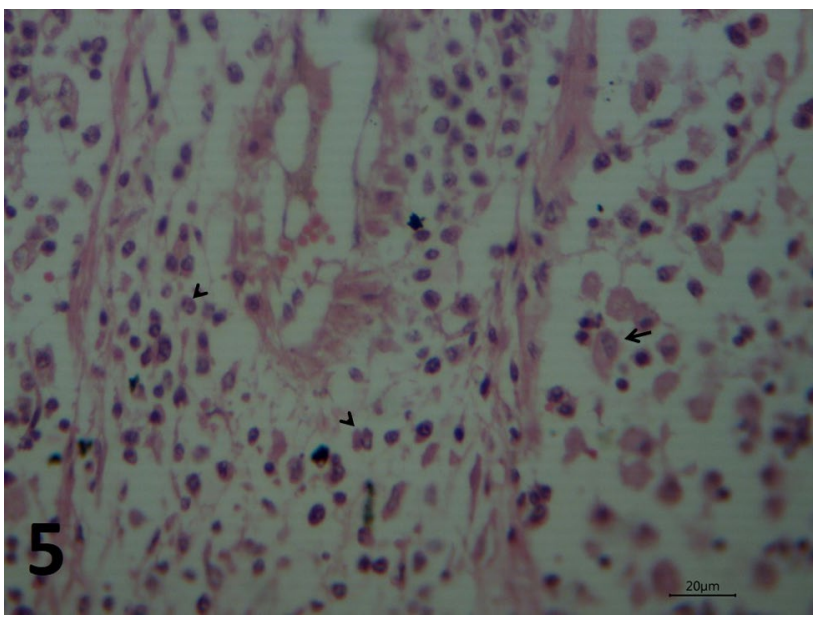

Fig. 5 Lymph node of cattle showing follicular depletion and proliferation reticulo-endothelial cells (arrow) beside expanded septae by exudate (arrow ahead) H\&E 


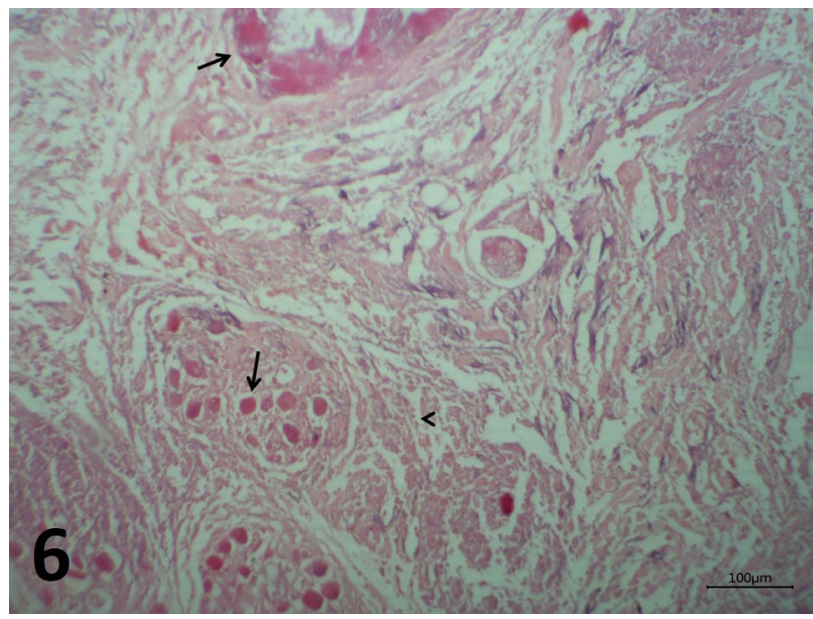

Fig. 6 Udder of cattle showing necrotic duct and alveolar epithelium with retained secretion (arrow) few inflammatory cells and interstitial fibrosis (arrow head) H\&E

cells mainly neutrophils together with bacterial colonies in the fibrosed stroma (Fig. 6). Testes revealed mild or arrest of spermatogenesis with various degenerative or necrotic changes in the testicular epithelium which infiltrated by neutrophil (orchitis), in addition to interstitial edema (Fig. 7). Focal necrotic hepatitis characterized by minute areas of coagulative necrosis with disseminated micro-thrombi in sinusoids and blood vessels and a few scattered neutrophils were observed (Fig. 8). Portal blood vessels exhibited vasculitis with proliferation of bile duct epithelium. Membrano-proliferative glumerulo-nephritis characterized by thickened glomerular basement membrane, proliferative mesangial cells, and contracted tufts in addition to interstitial fibroblasts containing numerous neutrophil replaced necrotic tubules could be seen in the renal cortex of kidneys of some cattle (chronic interstitial nephritis) (Fig. 9). Renal arteries showed vasculitis with ischemic nephrotic changes in the

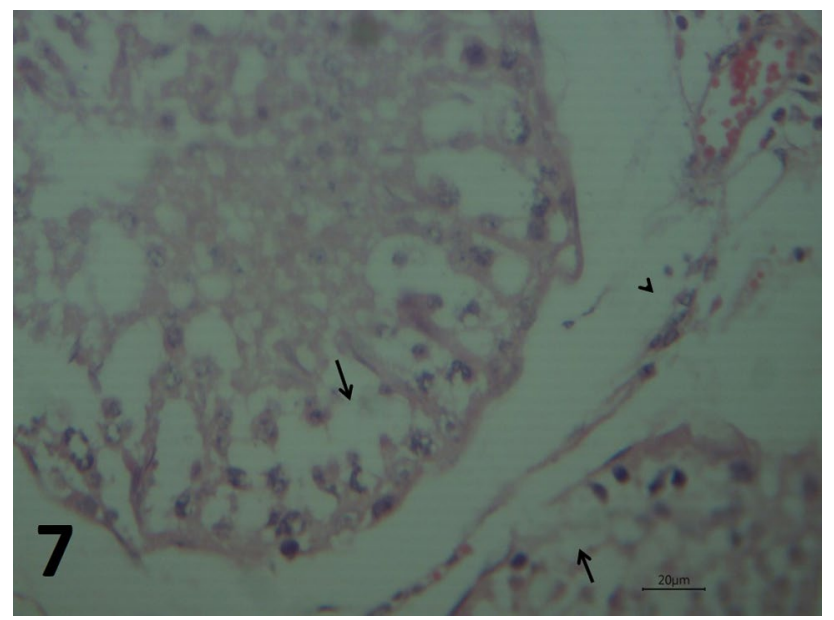

Fig. 7 Testis of a bull showing degeneration and necrosis of tubular epithelium and spermatozoa beside interstitial edema (arrow) H\&E

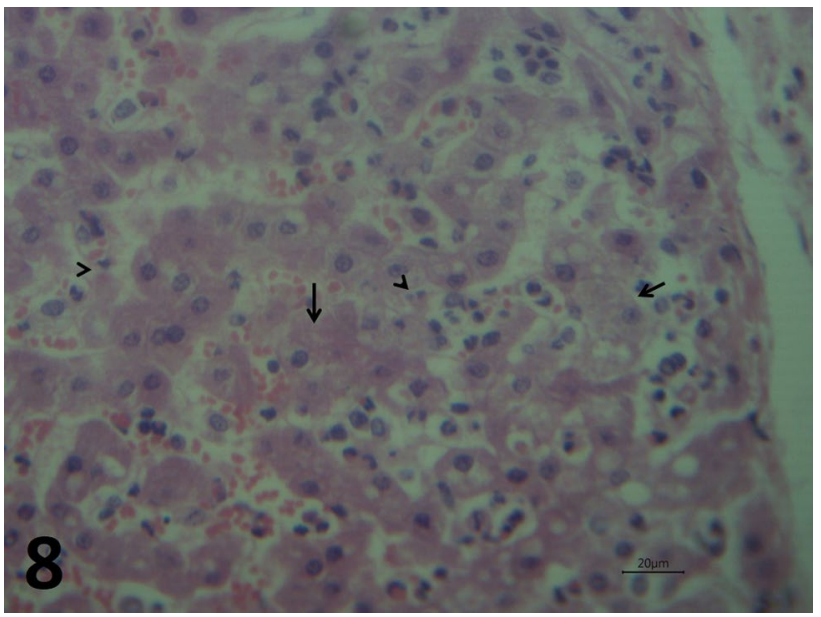

Fig. 8 Liver of cattle showing minute hepatic necrosis (arrow) disseminated micro-thrombi in sinusoid (arrow head) and few neutrophils infiltrations $\mathrm{H} \& \mathrm{E}$

adjacent parenchyma. Heart of the majority of necropsied cattle had inter and intra muscular edema with partial myocardial degeneration (Fig. 10). Moreover, serous atrophy of coronary fat with thrombosis of some blood vessels was encountered. Interstitial or bronchopneumonia accompanied by atelectasis and necrotic tracheitis were encountered in a few cases. The main noticeable histopathology lesions score in the infected animals were recorded (Table 2).

\section{Discussion}

This surveyed study declared still existing of LSD infection in both dairy and fattening flocks in Egypt with induction of severe economic losses among infected herds. The

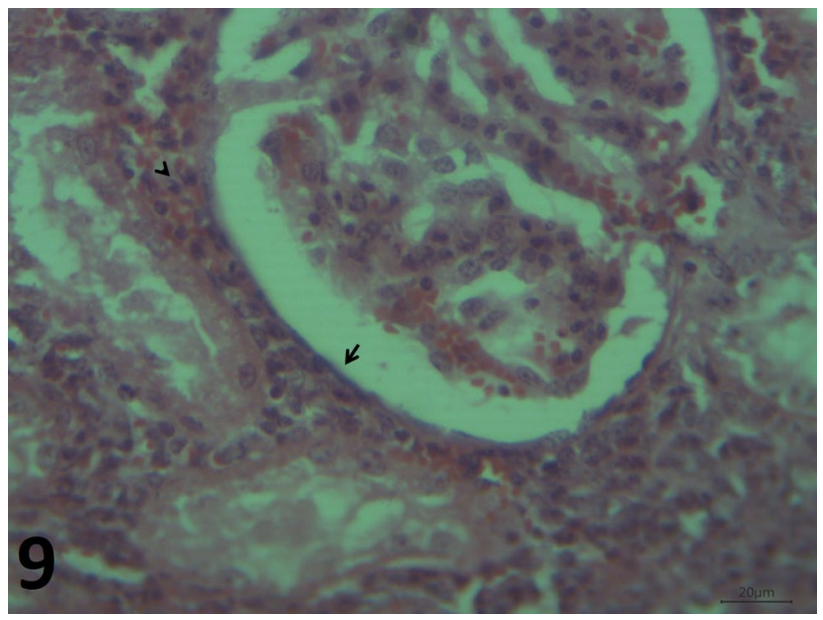

Fig. 9 Kidney of cattle showing thickened glomerular basement membranes (arrow) interstitial neutrophilic aggregation (arrow head) and necrotic tubules H\&E 


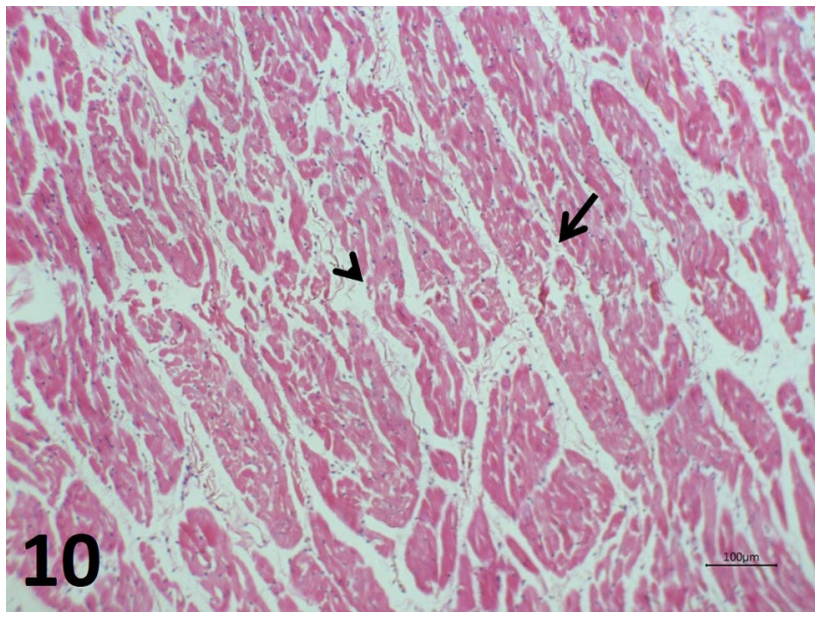

Fig. 10 Heart of cattle showing inter and intramuscular edema (arrow) and partial myocardial degeneration (arrow head) H\&E

detectable clinical signs among Frisian cattle flocks varied in intensity and duration from mild to moderate and even severe with average 26 . A total of $28 \%$ morbidity among all examined flocks. The majority of infected cattle recovered, and a few died or emergency slaughtered with average total mortality $6.59 \%$. Our results are in agreement with Amin et al. (2015) and Salib and Osman (2011). Lower morbidity ratio could be due to individual susceptibility, immunological resistance, and/or the capacity of vector species in LSDV transmission (European Food Safety et al. 2020). Recorded deaths in our study may follow viremia and secondary bacterial infection. Moreover, disseminated involvement of vital organs as parechymatous organs followed viremia may play role in raising mortalities.

Regarding to gross lesions, the parenchymatous organs usually enlarged, pale, and contains grayish areas besides consolidating pulmonary lobes. Skin of udder and scrotum were involved with edematous testis and indurated firm quarter of some mammary tissue. Involvement of mammary gland and testis in this study may be due to extension of lesions from skin of udder and scrotum. Our finding are in agreement with Amenu et al. (2018) and European Food Safety (2015). Hepatic, renal, and lung lesions in our work may be due to disseminated viral infection and variation of
Table 2 Type, prevalence, percentage, and intensity of histopathologylesions among different organs of LSD necropsied cattle

\begin{tabular}{|c|c|c|c|c|}
\hline \multirow[t]{2}{*}{ Organ } & \multicolumn{4}{|l|}{ Histopathology lesions } \\
\hline & Type & Prevalence & Percentage & Intensity \\
\hline \multirow[t]{3}{*}{ Skin } & Pox lesion & $12 / 18$ & 66.66 & +++ \\
\hline & Intra-cytoplasmic eosinophilic inclusion bodies & $6 / 18$ & 33.33 & ++ \\
\hline & Dermal edema and hemorrhage & $8 / 18$ & 44.44 & ++ \\
\hline Subcutaneous tissue & Exudative cellulitis & $10 / 18$ & 55.55 & +++ \\
\hline \multirow[t]{2}{*}{ Skeletal muscles } & Necrotic myositis & $14 / 18$ & 77.77 & ++ \\
\hline & Vasculitis and thrombosis & $13 / 18$ & 72.22 & + \\
\hline \multirow[t]{3}{*}{ Lymph node } & Lymphadenitis & $16 / 18$ & 88.88 & +++ \\
\hline & Depletion and necrosis of lymphocytes & $15 / 18$ & 83.33 & +++ \\
\hline & Proliferation of reticuloendothelial cells & $5 / 18$ & 27.77 & ++ \\
\hline \multirow[t]{3}{*}{ Udder } & Necrotic alveolar duct & $5 / 6$ & 83.33 & ++ \\
\hline & Mastitis & $4 / 6$ & 66.66 & ++ \\
\hline & Fibrosis of stroma & $2 / 6$ & 33.33 & \\
\hline \multirow[t]{2}{*}{ Testes } & Degeneration or necrotic seminiferous tubules & $4 / 4$ & 100 & +++ \\
\hline & Orchitis & $3 / 4$ & 75 & + \\
\hline \multirow[t]{3}{*}{ Liver } & Necrotic hepatitis & $14 / 18$ & 77.77 & ++ \\
\hline & Vasculitis of blood vessels & $11 / 18$ & 61.11 & + \\
\hline & Disseminated thrombosis & $3 / 18$ & 16.66 & + \\
\hline \multirow[t]{3}{*}{ Kidneys } & Membrano-proliferative glomerulo-nephritis & $10 / 18$ & 55.55 & ++ \\
\hline & Vasculitis & $9 / 18$ & 50 & + \\
\hline & Chronic interstitial nephritis & $6 / 18$ & 33.3 & + \\
\hline \multirow[t]{3}{*}{ Heart } & Inter and intra muscular edema & $8 / 18$ & 44.44 & + \\
\hline & Myocardial degeneration & $9 / 18$ & 50 & + \\
\hline & Myxomatous degeneration of the coronary fat & $7 / 18$ & 38.88 & + \\
\hline \multirow[t]{2}{*}{ Spleen } & Lymphoid depletion and necrosis & $7 / 18$ & 38.88 & ++ \\
\hline & Proliferation of reticuloendothgelial cells & $8 / 18$ & 44.44 & ++ \\
\hline Trachea & Tracheitis & $3 / 18$ & 16.66 & + \\
\hline \multirow[t]{3}{*}{ Lung } & Bronchopneumonia & $8 / 18$ & 44.44 & ++ \\
\hline & Interstitial pneumonia & $8 / 18$ & 44.44 & ++ \\
\hline & Atelectasis & $4 / 18$ & 22.22 & + \\
\hline
\end{tabular}

Intensity codes: Mild (+), moderate $(++)$, and severe $(+++)$ 
viral tropism which may follow some genetic abnormalities or mutation. We noticed broad dissemination of infection which involves also spleen. Aforementioned finding may follow leukocyte trafficking of pox virus as seen in sheep pox infection. Also, our observation was supported by PCR and fusion gene for viral isolate from internal organs.

Our microscopic lesions in epidermis and skin appendages of examined organs characterize specific pox changes with intra-cytoplasmic inclusion bodies. Similar findings were reported by Alsalihi (2014) and Alsalihi and Hassan (2015). The prevalence of cutaneous changes that was $66.66 \%$ indicates high tropism of epidermal cells. Moreover, lower prevalence $(33.33 \%)$ of specific intra-cytoplasmic inclusion bodies may attribute to progression of pock lesions and early detection. Deep extension of lesions to involve subcutaneous tissue and skeletal muscle which lead to edema and necrotic myositis was recorded in our work. Aforementioned lesions may due to vasculitis and thrombosis which resulted in ischemia with or without calcification and secondary bacterial infection. Our results are in partial agreement with (Amin et al. 2015). Lymphoid organs in our work showed intense lymphoid depletion, necrosis, and proliferation of reticulo-endothelial cells together with or without inflammatory response exudate lymphadenitis. Our results disagree with El-Neweshy et al. (2013) who recorded lymphoid hyperplasia of lymph node with presence of foamy macrophages. Aforementioned lesions indicate immunosuppressive effect which enhance viral dissemination to various internal organs and secondary bacterial infection. High prevalence of necrotic myositis and thrombosis (77.77\%) indicated intensity of vascular endothelial injury and ischemia which usually follows by secondary bacterial infection from skin and persistent of pustule pock lesions. Intense and great evidence of superficial lymphadenitis (88.88\%) could be follow immune suppressive effect of capripoxvirus after leukocyte trafficking and virus replication within the immune organs (spleen and lymph nodes).

The lesions in lactating and immature mammary glands included necrotic acini and alveolar ducts with inflammatory cell infiltration suggestive for mastitis. The high prevalent of mastitis $(66.66 \%)$ in lactating and immature udder declared progressive and dissemination of capripoxvirus and contamination of teat orifices. Higher testicular lesions ( $75 \%$ orchitis) in examined bulls represented by degenerated and necrotic seminiferous tubules infiltrated by neutrophils with mild or arrest of spermatogenesis. A few authors partially accordance with our results (European Food Safety 2015). Specified hepatic lesions in the form of focal hepatitis $(77.77 \%)$ with disseminating of micro-thrombi in blood vessels $(16.6 \%)$ and vasculitis $(61.11 \%)$ could be seen. The encountered vasculitis could be resulted from immune complex deposition in capillaries, arterioles and post-capillary venules (Zachary and McGavin 2017). The hepatic and renal changes in our examined cases characterized by ischemic changes following viremia and vasculitis or thrombosis which follow endothelial damage (Amin et al. 2015). The first encountered membrano-proliferative glomerulo-nephritis $(55.55 \%)$ and vasculitis $(50 \%)$ could attribute to deposition of immune complex in glomeruli (immune mediated) and vascular wall or endothelial injury from viral replication. Similar findings were reported by Jones et al. (1997) who mentioned that sheep pox characterized by necrotizing vasculitis with necrotic foci in some viscera. Moreover, focal inflammatory cells in interstitial or fibrosis usually follow ischemic lesions at the end stage of and kidneys diseases and blood supply of tubules and interstitial via glomeruli (chronic interstitial nephritis). Prevalence of heart lesions of some necropsied animals was represented by inter muscular edema (44.4\%) and partial myocardial degeneration (50\%) with thrombosis of some blood vessels (38.88\%). Moreover, serous atrophy of the coronary fat was less common and seen in chronic and emaciated cases. Encountered myocardial lesions may follow vascular injury of the blood vessels. These findings were in accordance with Zachary and McGavin (2017) who mentioned that capripoxvirus replicates endothelial cells resulting indirect injury and acute inflammatory response.

Respiratory tracts including trachea and lungs suffered from necrotic tracheitis (16.66\%) and interstitial or bronchopneumonia (44.44\%) and atelectasis (22.22\%). Respiratory system involvement followed hematogenous spread with involvement of pulmonary endothelial cells and macrophage which produce some inflammatory cytokines. Also, involvement of respiratory system indicates capripoxvirus of cattle became more virulent with extension of virus to bronchial or alveolar epithelial. Our results agreed with Zachary and McGavin (2017) who mentioned that pneumonia may be accompany systemic pox virus induce disease. Secondary bacterial infection increase intensity of various encountered lesions follows vial immunosuppression.

\section{Conclusions}

It could be concluded that LSD still prevalent in the Delta of Egypt with broad dissemination in various visceral organs of the infected cattle and became more virulent with induction of variable intensity lesions which impact in great economic losses among infected flocks in Egypt.

Author contribution AAA collected, analyzed, and interpreted the cattle data and contributor in writing the manuscript. Revised the datasets and designed the methodology protocol. ANFN contribute in designed methodology and writing the manuscript and revised the manuscript datasets. HAES was responsible for sample collection, sample storage, writing the manuscript and revised the datasets and designed the methodology protocol. RIM was responsible for sample collection sample storage, interpreted and revised the datasets and designed the methodology protocol and writing the manuscript. All authors read, revise and approved the final manuscript. 
Availability of data and material The all datasets used and analyzed during the current study are available from the corresponding author on reasonable request.

\section{Declarations}

Ethical approval Study was achieved in accordance with the standards set by Animal Research Ethics Usage Initiative at Zagazig University, Egypt, and experimental protocols were approved by the official animal ethics agency.

Consent to participate All authors agree on the participation.

Conflict of interest The authors declare no competing interests.

\section{References}

Ali A, Elmowalid G, Abdel-Glil M, Sharafeldin T, Abdallah F, Mansour S, Nagy A, Ahmed B, Abdelmoneim M (2015) Etiology and pathology of epidemic outbreaks of avian influenza H5N1 infection in Egyptian chicken farms. Pol J Vet Sci 18:779-786. https:// doi.org/10.1515/pjvs-2015-0101

Ali AA, Esmat M, Attia H, Selim A, Abdel-Hamid YM (1990) Clinical and pathological studies on lumpy skin disease in Egypt. Vet Rec 127:549-550

Alsalihi K (2014) Lumpy Skin disease: Review of literature MRSVA $3: 6-23$

Alsalihi KA, Hassan IQ (2015) Lumpy skin disease in Iraq: study of the disease emergence transbound. Emerg Dis 62:457-462. https:// doi.org/10.1111/tbed.12386

Amenu A, Feyisa B, Gezali A, Derej A (2018) Review on epidemiological aspects and economic impact of lumpy skin disease. J Dairy Vet Sci 7:1-8. https://doi.org/10.19080/JDVS.2018.07.555716

Amin A, El-Nahas E, El-Mashed A-E (2015) Pathological and virological studies on an outbreak of lumpy skin disease among cattle in Kalubia Governorate-Egypt Journal of Advanced. Vet Res 5:165-175

Binepal YS, Ongadi FA, Chepkwony J (2001) Alternative cell lines for the propagation of lumpy skin disease virus. Onderstepoort J Vet Res 68:151-153

El-Neweshy M, El-Shemey TM, Youssef S (2013) Pathologic and immunohistochemical findings of natural lumpy skin disease in Egyptian Cattle. Pakistan Veterinary Journal 33:60-64

Elseweidy MM, Ali AA, Elabidine NZ, Mursey NM (2017) Effect of zinc gluconate sage oil on inflammatory patterns and hyperglycemia in zinc deficient diabetic rats. Biomed \& Pharm 95:317-323. https://doi.org/10.1016/j.biopha.2017.08.081

Elseweidy MM, Mohamed HE, Elrashidy RA, Atteia HH, Elnagar GM, Ali A (2019) Potential therapeutic roles of 10-dehydrogingerdione and/or pentoxifylline against calcium deposition in aortic tissues of high dietary cholesterol-fed rabbits. Mol \& Cell Biochem 453(1-2):131-142. https://doi.org/10.1007/s11010-018-3438-1

European Food Safety A et al (2020) Lumpy skin disease epidemiological report IV: data collection and analysis. EFSA J 18:e6010. https://doi.org/10.2903/j.efsa.2020.6010

European Food Safety APoAHW (2015) Scientific opinion on lumpy skin disease. EFSA J 13:3986. https://doi.org/10.2903/j.efsa.2015. 3986

Jarullah B (2015) Incidence of lumpy skin disease among Iraqi cattle in Waset Governorate, Iraq Republic. BA Jarullah Int J Adv Res 3(4):936-939

Jones T, Hunt R, King N (1997) Veterinary Pathology. $6^{\text {th }}$ edn. Wiley-Blackwell

Limon G, Gamawa AA, Ahmed AI, Lyons NA, Beard PM (2020) Epidemiological characteristics and economic impact of lumpy skin disease. Sheeppox and Goatpox among subsistence farmers in Northeast Nigeria. Front Vet Sci 7:8-8. https://doi.org/10.3389/ fvets. 2020.00008

Neamat-Allah AN (2015) Immunological, hematological, biochemical, and histopathological studies on cows naturally infected with lumpy skin disease. Vet World 8:1131-1136. https://doi.org/10. 14202/vetworld.2015.1131-1136

Neamat-Allah ANF, Ali AA, Mahmoud EA (2020) Jeopardy of Lyssavirus infection in relation to hemato-biochemical parameters and diagnostic markers of cerebrospinal fluid in rabid calves. Comp Clin Pathol 29(2):553-560. https://doi.org/10.1007/ s00580-020-03094-z

Neamat-Allah ANF, Mahmoud EA (2019) Assessing the possible causes of hemolytic anemia associated with lumpy skin disease naturally infected buffaloes. Comp Clin Pathol 28:747-753. https://doi.org/10.1007/s00580-019-02952-9

Salib F, Osman A (2011) Incidence of lumpy skin disease among Egyptian cattle in Giza Governorate. Egypt Vet World 4:162-167

Stalker MJ (2007) Pathologic basis of veterinary disease, $4^{\text {th }}$ ed. Can Vet J 48:724-724

Wallace DB, Weyer J, Nel LH, Viljoen GJ (2007) Improved method for the generation and selection of homogeneous lumpy skin disease virus (SA-Neethling) recombinants. J Virol Methods 146:52-60. https://doi.org/10.1016/j.jviromet.2007.06.004

Zachary J, McGavin M (2017) Pathologic Basis of Veterinary Disease, 6th edn. Elsevier, St Louis

Zeedan GSG, Mahmoud AH, Abdalhamed AM, El-Razik KAE-HA, Khafagi MH, Zeina HAAA (2019) Detection of lumpy skin disease virus in cattle using real-time polymerase chain reaction and serological diagnostic assays in different governorates in Egypt in 2017. Vet World 12:1093-1100. https://doi.org/10.14202/ vetworld.2019.1093-1100

Publisher's Note Springer Nature remains neutral with regard to jurisdictional claims in published maps and institutional affiliations. 